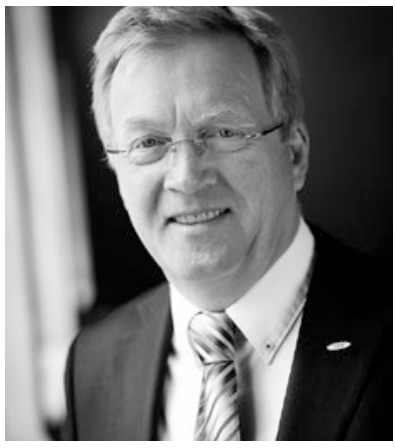

Andreas Westerfellhaus

Präsident des Deutschen Pflegerats
Deutscher Pflegerat e.V.

Bundesarbeitsgemeinschaft

Pflege- und Hebammenwesen

In Kooperation mit

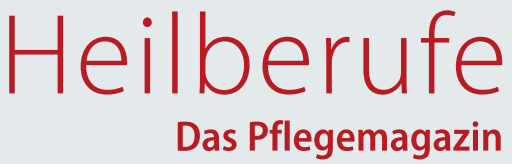

\title{
Editorial
}

\section{Herzliche Einladung zum Deutschen Pflegetag 2017 - dem Jahr der Bundestagswahl}

D er Deutsche Pflegetag ist die zentrale Veranstaltung für die professionell Pflegenden im Jahr 2017! Er findet vom 23. bis 25. März 2017 in der STATION-Berlin statt. Hier kann die Pflege Zeichen setzen. Seien Sie hierzu herzlich eingeladen.

Die Klärung der Personalbemessung in der Pflege, im Krankenhaus und in Pflegeeinrichtungen, ist eine der entscheidenden $\mathrm{Zu}$ kunftsaufgaben. Und hätte schon längst erledigt gehört. Wie viele Mitarbeiterinnen und Mitarbeiter sind genug und woher kommen sie? Liegt die Lösung des Fachkräftemangels in der Pflege im Ausland? Der Deutsche Pflegetag 2017 wird sich ausführlich mit diesen Themen beschäftigten. Weiter wird es um die „vielen Gesichter der Demenz" und die „Kommunalisierung der Pflege“ sowie um „Schwarze Schafe in der Pflege“ gehen. Gleichfalls im Mittelpunkt des Deutschen Pflegetags 2017 wird die große Rolle der Ethik in der Gesundheitsversorgung und der Pflege spielen. Aber auch Themen wie, „Was geschieht, wenn Mama oder Papa krank sind?“ sind Inhalt des umfangreichen und wertvollen Kongressprogramms.

Auch in diesem Jahr geht es darum, die Pflege mit starken Partnern zu stärken. Und gleichfalls zusammen mit rund $8.000 \mathrm{zu}$ erwartenden Besucherinnen und Besuchern deutlich zu machen, dass ohne die professionell Pflegenden nichts läuft. Die Politik und die Kostenträger müssen endlich erkennen, dass wir es sind, die die Leistungen in allen Sektoren erst sicherstellen. Hierfür gilt es auch im Jahr 2017 deutliche Zeichen zu setzen.

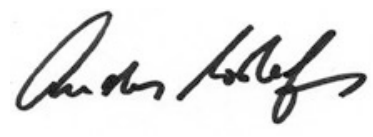

Andreas Westerfellhaus

Präsident des Deutschen Pflegerats

\section{IM FOCUS}

\section{Ohne Pflegepersonal wird es keine Pflege geben}

Der sechste Pflegebericht macht eines deutlich: Das Thema Personal ist das wichtigste Thema für die Sicherung einer qualitativ hochwertigen Pflege - heute und in der Zukunft. Es wäre wünschenswert gewesen, wenn sich der Gesetzgeber in den letzten Jahren mehr mit diesem Thema beschäftigt hätte. Denn ohne Pflegepersonal wird es keine Pflege geben. Dieser zentrale Mechanismus wird nach wie vor bei der Gesetzgebung massiv vernachlässigt. Es muss endlich verstanden werden, dass kein Gesetz mehr verabschiedet werden darf, welches nicht klipp und klar deutlich macht, mit welchem Personal die im Gesetz versprochenen Leistungen erbracht werden sollen.

Eine weitere entscheidende Zukunftsaufgabe ist die Klärung der Arbeitsbedingungen in der Pflege. Der Deutsche Pflegerat fordert ein auf Bundesebene angesiedeltes umfassendes Forschungsvorhaben zur zentralen Frage "Wie sieht angesichts knapper Personalkapazitäten die Arbeitsgestaltung und Arbeitsorganisation der Pflege in der Zukunft aus?". Diese Frage gilt es schnell und umfassend zu beantworten.

Die Ergebnisse der Einführung des Strukturmodells zur Entbürokratisierung der Pflegedokumentation haben gezeigt, was möglich ist, wenn eine solche Aufgabe zielgerichtet auf Bundesebene angegangen wird. Das nächste brennende Thema muss die Dienstplangestaltung in der Pflege sein. Wie kann diese so gestaltet werden, dass ein „Recht auf frei" tatsächlich auch ein solches Recht bleibt? Darin liegt auch ein großes Thema für mehr Motivation der professionell Pflegenden.

Franz Wagner

Vize-Präsident des Deutschen Pflegerats (DPR) 